\title{
THE FAA: A TOMBSTONE AGENCY? PUTTING THE NICKNAME TO THE TEST
}

\author{
Rebecca K. Lutte and Brent D. Bowen \\ University of Nebraska at Omaha
}

\begin{abstract}
The purpose of this research was to investigate Federal Aviation Administration (FAA) activity before and after six catastrophic airline accidents to examine the alleged reactive policysetting reputation of the FAA. Actions reviewed were regulatory, inspection, and enforcement activities. The study revealed that change in agency activity does occur following an accident. The location of the event appears to influence the direction of change. When accidents occurred within the United States, FAA activity increased following the accident. The opposite occurred for airline accidents outside the U.S. The increase in FAA activity following U.S. based events, supports the reactive, tombstone agency reputation the FAA has acquired.

In addition, the research revealed nine FAA activities judged by industry experts as having the ability to improve safety in the airline industry. Inspections and certificate actions are considered activities that will improve safety. Regulatory actions, fines, warning notices, and letters of correction were judged as non-safety enhancing activities. The result of this research was an increased understanding of how the FAA responds to airline accidents and the consequences of the response.
\end{abstract}

\section{THE REPUTATION OF THE FAA}

The Federal Aviation Administration (FAA) is the agency charged with safety oversight in the aviation industry. The organization is under fire in the media for not taking actions to meet this goal. The FAA has been criticized for being overly responsive to external actors. Some believe responsiveness to media, following the ValuJet accident, played a role in the airline $s$ shut down and subsequent resignations of several key FAA officials (Shifrin, 1996a). During ValuJet hearings, Former Senator Cohen told the subcommittee, the FAA s problems are much deeper than ValuJet and its troubled safety program. The agency s continuous refusal to acknowledge its shortcomings is indicative of a managerial culture that denies problems exist, defends the status quo and uses public relations spins to deflect criticism (Phillips, 1996, p. 31). Criticism exists over the amount of influence the industry, particularly airlines, has over the FAA (Ullmann, 1996; Bryant, 1996; Gleckman, 1996). In fact, the FAA admits it works slowly because it needs to balance the benefits of safety changes with airlines and crews interests (FAA s snail space, 1999). Critical of the industry influence over FAA policy, an assistant U.S. attorney, after several investigations of FAA positions on safety policies, said to former 
FAA official, Anthony Broderick, You are supposed to regulate, not represent, the airlines (Cary, Hedges, \& Walsh, 1996, p. $50)$.

Others have gone so far as to say that the FAA itself is a safety problem (Glieck, 1996). The organization was described by one author (Ullmann, 1996) as secretive FAA management, whose military mind set, industry sympathies, and resistance to change give critics fits (p. 39). A Newsweek article also presents the claim that the FAA is unresponsive. Thanks to inept management, bureaucratic inertia, and the constant tugging of powerful economic interests, the FAA remains one of the government $\mathrm{s}$ least adaptive agencies (Levinson, Underwood, \& Turque, 1996, p. 46). The agency has been accused of possessing a tombstone mentality of acting only after a tragedy (Ullmann, 1996, p. 39). In the past few years, the FAA has come under fire for being reactive and not proactive, responding to safety concerns only after a catastrophic accident has occurred (Phillips, 1995; Shifrin, 1996b).

\section{RESEARCH QUESTIONS}

While criticism of the FAA certainly exists, surprisingly, no previous research has been located that addresses these claims. This research provides the first step toward examining the reputation the FAA has developed for their alleged reactive policysetting practices. An exploration of FAA actions before and immediately after a tragic event, such as an airline accident, will address these issues. Furthermore, why study crises at all if not to reduce the occurrence of future events? Perhaps more critical than knowing whether policy change occurs following a crisis is knowing what consequences, if any, such policy action brings. Take for example the following scenario. A crisis occurs, the crash of an airliner. The FAA responds by increasing inspections of airlines. Do industry experts believe such activity (increased inspections) will enhance the safety of the airline industry? To explore FAA policy practices, the following research questions were developed.

1. Does a change in agency activity occur following a crisis event?

2. Is agency activity perceived to improve safety in the airline industry?

\section{METHODOLOGY}

To address the research questions, a method was required that would allow for analysis of FAA activity variables and for establishing the importance of these variables to improving safety. The appropriate method should (a) provide comparable measures of agency activity before and after an accident, (b) result in determination of relative importance of variables regarding ability to improve airline safety, and (c) be congruent with publicly available data.

Given the criteria, the method selected was a weighted average. Weighted average development begins with the use of expert opinion (Clark \& Friedman, 1982; McMeniman, 1990; Bowen, Headley \& Luedtke, 1992) to determine importance weights. Each weight is then applied to the associated data. These values are added together and the total is divided by the sum of all the weights. The standard formula for the weighted average $(x)$ is:

$$
\mathrm{x}=\frac{\underline{\mathrm{w}}_{1}}{\mathrm{X}_{1}} \underline{\underline{\mathrm{X}_{2}}} \frac{\mathrm{w}_{2}}{\mathrm{X}_{1}} \underline{\mathrm{X}_{2}}+\ldots \ldots+\mathrm{w}_{\underline{\mathrm{k}}} \underline{\mathrm{X}_{\mathrm{k}}}=\frac{\sum \mathrm{wX}}{\sum \mathrm{w}}
$$


where $\mathrm{w}$ represents the associated weight for variable X (Spiegel, 1996, p. 59). The weighted average has been used in the field of aviation to develop the now well-known and highly-publicized Airline Quality Rating (Bowen, et.al., 1992). Using this methodology would provide the aviation industry with a measure of FAA response to accidents. The methodology would, as noted by Bowen, et. al (1992), provide such information in a timely manner using publicly-available data. The FAA has expanded public access to airline safety data. The release of information about individual carriers is in response to a call by the public and members of Congress for more safety information (Phillips, 1997). The move to release information was prompted by a deadly year for U.S. airlines, the crashes of ValuJet 592 and TWA 800 in 1996.

The standard weighted average formula can be calculated using FAA activity. Weights, indicating the perceived importance of each FAA activity to improving airline safety can be associated with publicly available FAA data. The end result is a single value indicating FAA agency activity as shown below.

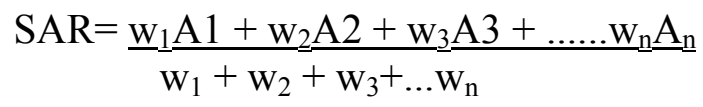

In this equation, (SAR) refers to safety activity rating, (w) refers to the weight assigned to each FAA activity (A). A separate value, or SAR, can be calculated for the time frame before and after each accident, allowing for comparison of agency activity.

To address question two, frequency distributions can be presented. The SAR is composed of factors that have been judged by industry experts, for importance in improving the safety of the airline industry.
A discussion of the weight assigned to these factors, indicating the importance of the activity to improving safety, along with examination of the level of activity using frequency distributions, will address question two. For example, if unannounced ramp inspections of flight operations are judged to be an important agency activity for the purpose of increased safety, the frequencies of this activity prior to and after accidents will be presented and discussed.

\section{Selecting the Variables for the SAR}

FAA activity was defined as policy outputs of the regulatory agency. Those policy outputs are regulatory, inspection, and enforcement activity. Safety experts consider fines and administrative actions important elements to consider when evaluating airline safety (Stoller, 2000). The regulatory category includes two measures of activity: number of Notice of Proposed Rulemakings (NPRMs) and number of new Federal Aviation Regulations (FARs). The inspection category includes en route inspections, facility inspections, record/log inspections, and spot/ramp (no notice) inspections. The inspections refer to activity or inspections of the following operations areas: flight operations and maintenance. The terms used here are derived from the FAA Enforcement Information System (EIS) code list (Department of Transportation, 1998). The enforcement category includes three measures of activity: occurrence of fines against airlines, occurrence of certificate actions (suspension or revocation), and written notifications of safety concerns and/or violations (warning notice or letter of correction).

The SAR was applied to an equal time frame before and after six accidents between 1988-1999. Accidents, as defined by the National Transportation Safety Board 
(NTSB), which involved United States based, Part 121 scheduled airlines and which resulted in 100 or more fatalities were selected. Not surprisingly, data show that most fatal airline accidents result in few lives lost or many lives lost. For example, from 1988 to 1999, (a) 13 accidents, each of which resulted in one to 25 fatalities, occurred; (b) three accidents, each of which resulted in 26 to 99 fatalities, occurred; and (c) six accidents, each of which resulted in 100 or more fatalities, occurred (National Transportation Safety Board, 2000). The purpose of using these years (1988-99) is to provide an adequate amount of accident data. Although accidents of this magnitude are rare, the time span will result in six accidents to review (see Appendix A).

\section{DATA COLLECTION \& ANALYSIS}

Expert opinion was gathered to determine the relative importance of each item to improving the overall safety of the airline industry. To gather the expert opinions, a questionnaire was constructed. The subject selection process resulted in a nonprobability, purposive sample. Subjects included airline safety department personnel from U.S. based, part 121 airlines, pilots from the primary pilot organizations including Allied Pilot Association (APA), Airline Pilots Association (ALPA), and International Association of Continental Pilots (IACP). FAA inspectors from regional and local FAA offices, investigators from NTSB regional offices, and university researchers with knowledge and research experience in areas including aviation safety, FAA activities, and airline operations were also included. Researchers were identified with the assistance of University Aviation Association (UAA). To minimize bias, no group was systematically under represented or over represented (Folz, 1996). A pre-test, considered a critical quality-control device (Folz, 1996, p.120), was conducted. Additionally, a test for scale reliability, Cronbach s Alpha (Cronbach, 1951) was calculated. According to Carmines and Zeller (1979), this test is an excellent technique for assessing reliability (p. 50) and therefore should be computed for any multiple-item scale ( $p$. 51). The values of coefficient alpha typically range from zero to one; the higher the value, the greater the internal consistency (Spector, 1992). Generally, a value of .6 or higher is acceptable but .8 or higher is preferred (Bowen, Headley, Kane, \& Lutte, 1999; Carmines \& Zellar, 1979). This research resulted in an alpha of .87. The mail questionnaire occurred in two phases and resulted in a usable response rate of $48 \%$, an acceptable rate according to the literature (Czaja \& Blair, 1996; Dooley, 1995; Folz, 1996). Questionnaire results are presented in Appendix B.

Once the results from the questionnaire were recorded, the mean response for each question was tabulated. The purpose of calculating the mean was to establish weights for each variable in the SAR formula. To continue building the formula, the activity data were entered. For each accident, FAA data were gathered for a period of 12 months prior to and 12 months following the accident. Birkland (1997) concluded that two years is an adequate time frame to monitor activity related to a crisis. Additionally, since the FAA has the ability to quickly initiate the variables described for this study, and as Kingdon (1995) points out, the window of opportunity for change following an aviation accident is short lived, a 12 month period is an appropriate length of time to gauge agency activity. Collection was conducted through the use of documents search, World Wide Web, and FAA 
database searches. Since the research resulted in a large amount of data, the FAA activity data have been summarized in two tables. The first, Appendix C, lists the activities that were judged by the experts as having the ability to enhance safety in the airline industry (mean response score of 5.0 or higher). Appendix D displays the same information for those activities judged as not having the ability to enhance safety.

With all the data collected, the SAR was applied to each of the six accidents. Research question one can be answered by comparing the SAR prior to each accident (to be known as $\mathrm{SAR}_{0}$ ) to the corresponding SAR following the accident $\left(\mathrm{SAR}_{1}\right)$. This was accomplished by using a simple ratio as seen below.

$$
\text { Change in } \mathrm{SAR}=\frac{\mathrm{SAR}_{1}-\mathrm{SAR}_{0}}{\mathrm{SAR}_{0}}
$$

The SARs for each accident for the year prior to (base year) and the year following the accident and the change in SARs are summarized in Table 1.

As the data in Table 1 reveal, patterns in agency activity do exist. Increases occurred following four of the accidents under review. All four of these accidents occurred in the United States.

\section{Table 1}

Change in SAR Scores (indicating FAA activity) From the Twelve Month Period Before the Accident $\left(\mathrm{SAR}_{0}\right)$ to the Twelve Month Period After the Accident $\left(\mathrm{SAR}_{1}\right)$

\begin{tabular}{|l|c|c|c|}
\hline \multicolumn{1}{|c|}{ Accident } & $\mathrm{SAR}_{0}$ & $\mathrm{SAR}_{1}$ & Change in SAR \\
\hline PanAM 103 & 124.3 & 110.0 & $-11.5 \%$ \\
\hline United 232 & 477.3 & 618.8 & $+29.6 \%$ \\
\hline USAir 427 & 370.1 & 388.6 & $+4.9 \%$ \\
\hline American 965 & 426.7 & 384.3 & $-9.9 \%$ \\
\hline ValuJet 592 & 47.3 & 173.9 & $+267.6 \%$ \\
\hline TWA 800 & 240.9 & 349.9 & $+45.2 \%$ \\
\hline
\end{tabular}


The SAR following the USAir crash increased by only $4.9 \%$. United 232 and TWA 800 resulted in larger changes of $29.6 \%$ and $45.2 \%$, respectively. The largest change occurred following the ValuJet 592 accident. The SAR increased by $267.6 \%$ in the twelve months after the DC-9 crash. In the two cases where decreases occurred, both accidents happened outside the United States. The PanAM 103 bombing over Lockerbie, Scotland and the American 965 crash in Cali, Colombia both resulted in a decrease in the Safety Activity Rating.

To answer question two, those activities perceived as having the ability to improve safety in the airline industry must be identified. This is accomplished by a review of the expert opinions. Industry experts were asked their opinions as to whether certain FAA activities will result in improved safety in the airline industry. The results of the questionnaire were used to identify the safety enhancing FAA activities.

Based on the mean scores from the industry expert responses, nine activities were identified as having the ability to improve safety in the airline industry. The nine activities are listed in Figure 1. The activities are rank-ordered, starting with those activities with the highest score for ability to improve safety in the airline industry.

1. Ramp/spot inspections - maintenance (5.5)

2. Facility inspections $¥$ maintenance (5.5)

3. Certificate suspension (5.4)

4. Certificate revocation (5.3)

5. Facility inspections $¥$ flight operations (5.3)

6. Enroute inspections $¥$ flight operations (5.2)

7. Ramp/spot inspections $¥$ flight operations (5.2)

8. Record/log inspections $¥$ maintenance (5.2)

9. Record/log inspections $¥$ flight operations (5.1)

Figure 1. FAA activities identified as safety enhancing.
Comparing the list of activities judged as safety enhancing, to the actual activity levels, is revealing. Increases in activity occurred in five of the nine activities judged as safety enhancing (see Appendix C). The greatest increase occurred in the highest ranked activity. Ramp/spot inspections of maintenance had the highest score for improving safety and had the largest overall increase in activity level following an accident. The overall postaccident increase in the number of maintenance ramp/spot inspections was 2,229 . No change occurred in two of the nine activities judged as safety enhancing; certificate suspensions and revocations. No such FAA actions took place during any time period under review. The two activities that experienced an overall decrease in activity, facility inspections of flight operations and enroute inspections, also experienced the smallest amount of change.

It is useful when answering question two, to also examine the data related to activities that were not perceived to improve safety. A summary of change in activity levels is provided in Appendix D. According to the data displayed for regulatory activities, issuance of FARs following accidents increased at a higher amount than issuance of post-accident NPRMs. FARs were rated by the industry experts as having a greater ability than NPRMs to improve safety. The enforcement categories that were judged as not having the ability to improve safety in the airline industry included fines, warning notices, and letters of correction. Three categories of fines were reviewed. The category of fine judged as least effective in improving safety was the type of fine imposed most often. Warning notices were issued more often than letters of correction although they were judged equally by industry experts.

After reviewing all activity levels, the answer to question two is yes, with one 
major exception. Agency activity is perceived to improve safety in the airline industry. Out of nine identified safety- enhancing activities, two experienced no change in activity, two decreased, and five increased. The exception is enforcement activity in the area of fines. One category of fines, those below $\$ 10,000$, showed an overall increase in activity following accidents. The enforcement activity received not only the lowest score for ability to improve safety in the airline industry of all three categories of fines, but also received the lowest score of all sixteen FAA activities. The type of fine most often enacted following an accident is the type of fine, and the FAA activity, judged as least effective in improving safety.

\section{CONCLUSIONS}

Based on the study, numerous conclusions regarding agency activity can be drawn. Below is a summary of these conclusions.

1. A change in FAA agency activity does occur following an accident. The location of the accident appears to influence the direction of change. When the event occurred outside the United States, the FAA activity levels decreased. Agency activity increased following accidents that occurred in the United States.

2. The increase in FAA activity levels, following catastrophic accidents in the United States, supports the reactive policy or "tombstone agency" reputation the agency has acquired. In every case where an accident occurred in the United States and resulted in more than 100 fatalities, a rise in agency activity was displayed.

3. Nine FAA activities were judged by industry experts as having the ability to improve safety in the airline industry. Inspections and certificate actions are considered activities that will improve safety in the airline industry.

4. Regulatory actions, fines, warning notices, and letters of correction were judged by experts as non-safety enhancing activities.

5. With the exception of fines, FAA postaccident activity is perceived to improve safety in the airline industry. The majority of the nine identified safety enhancing activities displayed an overall increase following a crisis event.

6. The FAA enforcement activity judged as least effective in ability to improve safety, was the most often used method of enforcement following accidents. Fines in an amount less than $\$ 10,000$ were the only category of fines to experience an overall increase following accidents.

\section{THE FAA: REPUTATION DESERVED}

What we know now is that the six cases examined here support the claim that FAA activity is driven not only by accidents, but by the location of those events. Another result of this study is the discovery that FAA agency behavior is perceived to improve safety. Inspections and certificate actions were activities judged as having the ability to improve safety. The majority of the safety enhancing activities displayed an overall increase following a catastrophic airline accident.

The FAA, however, should reconsider use of fines. Following accidents, the type of fine most often imposed by the FAA was a fine below $\$ 10,000$. These fines were judged as least effective of all FAA 
actions in ability to improve safety. Additionally, since large fines (those above $\$ 100,000)$ are rarely imposed, perhaps such fines should serve as a red flag to the FAA. A fine of such a substantial amount may be a signal of a growing safety problem. Case-inpoint, the only such fine imposed during the period under review for this study was a onetime $\$ 200,000$ fine against ValuJet in the 12 months before the crash of Flight 592. Perhaps the FAA and airline managers should consider such enforcement actions as cause for concern.

\section{TAKING IT TO THE NEXT LEVEL}

Results here prompt many new questions. For example, why the change in action following crashes occurring elsewhere in the world? The FAA still has control over the carriers involved in those accidents. Why not exercise it? Perhaps it relates to investigation jurisdiction or information access? Additionally, why did such a large increase in FAA activity (276\%) occur following the ValuJet crash? Perhaps intense media coverage played a role. Does the size of the carrier prompt differences in action? Another question can be raised regarding the FAA use of fines in small amounts. Why would the FAA focus on actions that are not perceived to improve safety? One may assume that FAA personnel are not aware of or do not agree with the experts evaluation of these non-safety enhancing activities. This study took the first step in exploring FAA accident related activity. Additional research should be conducted to explore these and other related research questions. 


\section{Appendix A}

Airline Accidents (Scheduled, Part 121) Resulting in 100 or More Fatalities for the Years 1988 1999

\begin{tabular}{|l|l|l|l|l|}
\hline \multicolumn{1}{|c|}{ Date } & \multicolumn{1}{|c|}{ Flight } & \multicolumn{1}{c|}{ Location } & Fatalities & \multicolumn{1}{c|}{ Description } \\
\hline $12 / 21 / 88$ & PanAM 103 & $\begin{array}{l}\text { Lockerbie, } \\
\text { Scotland }\end{array}$ & 270 & 747 terrorist bombing \\
\hline $7 / 19 / 89$ & United 232 & Sioux City, IA & 111 & DC-10 loss of hydraulics \\
\hline $9 / 8 / 94$ & USAir 427 & Aliquippa, PA & 132 & 737 roll over \\
\hline $12 / 20 / 95$ & $\begin{array}{l}\text { American } \\
965\end{array}$ & Cali, Columbia & 160 & $\begin{array}{l}757 \text { controlled flight into } \\
\text { terrain }\end{array}$ \\
\hline $5 / 11 / 96$ & ValuJet 592 & Miami, FL & 110 & $\begin{array}{l}\text { DC-9 hazardous materials } \\
\text { fire }\end{array}$ \\
\hline $7 / 17 / 96$ & TWA 800 & Moriches, NY & 230 & 747 mid-air explosion \\
\hline
\end{tabular}

Source: (National Transportation Safety Board, 2000) 


\section{Appendix B}

Summary of Questionnaire Results (reported by frequency of responses) Indicating Level of Agreement Regarding Ability of Activity to Improve Safety in the Airline Industry

\begin{tabular}{|l|l|l|l|l|l|l|l|l|}
\hline & $\begin{array}{l}\text { Str. } \\
\text { Disagree }\end{array}$ & $\begin{array}{l}\text { Mod. } \\
\text { Disagree }\end{array}$ & $\begin{array}{l}\text { Slt. } \\
\text { Disagree }\end{array}$ & Ntrl & $\begin{array}{l}\text { Slt. } \\
\text { Agree }\end{array}$ & $\begin{array}{l}\text { Mod. } \\
\text { Agree }\end{array}$ & $\begin{array}{l}\text { Str. } \\
\text { Agree }\end{array}$ \\
\hline Regulatory & \multicolumn{7}{|l|}{} \\
\hline 1: FARs & 6 & 5 & 1 & 13 & 15 & 13 & 5 \\
\hline 2: NPRMs & 8 & 7 & 5 & 16 & 10 & 10 & 2 \\
\hline Enforcement
\end{tabular}




\section{Appendix C}

Change in FAA Activity Levels (activities judged as having the ability to improve safety in the airline industry) From the Year Before the Accident to the Year Following the Accident

\begin{tabular}{|l|l|l|l|l|l|l|l|l|}
\hline & \multicolumn{6}{|c|}{ Inspection Activity } \\
\hline & $\begin{array}{l}\text { Ramp: } \\
\text { Maint. }\end{array}$ & $\begin{array}{l}\text { Facility: } \\
\text { Maint. }\end{array}$ & $\begin{array}{l}\text { Facility: } \\
\text { Flight }\end{array}$ & $\begin{array}{l}\text { Enrt. } \\
\text { Insp. }\end{array}$ & $\begin{array}{l}\text { Ramp: } \\
\text { Flight }\end{array}$ & $\begin{array}{l}\text { Records: } \\
\text { Maint. }\end{array}$ & $\begin{array}{l}\text { Records: } \\
\text { Flight }\end{array}$ \\
\hline Accidents & \multicolumn{7}{|l|}{} \\
\hline ValuJet 592 & 953 & 100 & $(1)$ & 54 & 48 & 102 & 8 \\
\hline United 232 & 1,522 & 127 & 71 & $(459)$ & 431 & 146 & 127 \\
\hline USAir 427 & $(70)$ & 8 & $(47)$ & 500 & $(127)$ & 29 & $(18)$ \\
\hline American 965 & $(192)$ & $(21)$ & $(36)$ & $(186)$ & $(100)$ & $(62)$ & $(13)$ \\
\hline TWA 800 & 127 & 16 & 3 & 99 & 26 & 55 & $(16)$ \\
\hline PanAM 103 & $(11)$ & 46 & $(26)$ & $(25)$ & $(53)$ & $(21)$ & $(14)$ \\
\hline $\begin{array}{l}\text { Airlines } \\
\text { Increased }\end{array}$ & 3 & 5 & 2 & 3 & 3 & 4 & 2 \\
\hline $\begin{array}{l}\text { Airlines } \\
\text { Decreased }\end{array}$ & 3 & 1 & 4 & 3 & 3 & 2 & 4 \\
\hline $\begin{array}{l}\text { Overall Change } \\
\text { in Activity }\end{array}$ & $\mathbf{2 , 2 2 9}$ & $\mathbf{2 7 6}$ & $\mathbf{( 3 6 )}$ & $\mathbf{( 1 7 )}$ & $\mathbf{2 2 5}$ & $\mathbf{2 4 9}$ & $\mathbf{7 4}$ \\
\hline
\end{tabular}

Note. Parentheses ( ) indicate a decrease in activity levels. 


\section{Appendix D}

Changes in FAA Activity Levels (activities judged as not having the ability to improve safety in the airline industry) From the Year Before the Accident to the Year Following the Accident

\begin{tabular}{|l|l|l|l|l|l|l|l|l|}
\hline & \multicolumn{2}{|c|}{ Regulatorv } & \multicolumn{5}{|c|}{ Enforcement } \\
\hline & FARs & NPRMs & $\begin{array}{l}\text { Fines }< \\
10 \mathrm{~K}\end{array}$ & $\begin{array}{l}\text { Fines } \\
10 \mathrm{~K} \text { to } \\
100 \mathrm{~K}\end{array}$ & $\begin{array}{l}\text { Fines } \\
>100 \mathrm{~K}\end{array}$ & $\begin{array}{l}\text { Warning } \\
\text { Notices }\end{array}$ & $\begin{array}{l}\text { Letters of } \\
\text { Correction }\end{array}$ \\
\hline Accidents & \multicolumn{7}{|l|}{} & \multicolumn{5}{|l|}{} \\
\hline PanAM 103 & 3 & 1 & $(1)$ & 0 & 0 & 4 & $(8)$ \\
\hline United 232 & 6 & $(1)$ & 4 & $(2)$ & 0 & 1 & 3 \\
\hline USAir 427 & 2 & $(2)$ & 1 & $(4)$ & 0 & 0 & 1 \\
\hline $\begin{array}{l}\text { American } \\
965\end{array}$ & 4 & 3 & 4 & $(3)$ & 0 & 1 & $(4)$ \\
\hline ValuJet 592 & 5 & 1 & 0 & 1 & $(1)$ & 0 & 0 \\
\hline TWA 800 & $(5)$ & $(1)$ & 4 & $(1)$ & 0 & 1 & 1 \\
\hline $\begin{array}{l}\text { Airlines } \\
\text { Increased }\end{array}$ & 5 & 3 & 4 & 1 & 0 & 4 & 3 \\
\hline $\begin{array}{l}\text { Airlines } \\
\text { Decreased }\end{array}$ & 1 & 3 & 1 & 4 & 1 & 0 & 2 \\
\hline $\begin{array}{l}\text { Overall } \\
\text { change in } \\
\text { activity }\end{array}$ & $\mathbf{1 5}$ & $\mathbf{1}$ & $\mathbf{1 2}$ & $\mathbf{( 9 )}$ & $\mathbf{( 1 )}$ & $\mathbf{7}$ & $\mathbf{( 7 )}$ \\
\hline
\end{tabular}

Note. Parentheses ( ) indicate a decrease in activity levels. 


\section{REFERENCES}

Birkland, T. A. (1997). After disaster: Agenda setting, public policy, and focusing events. Washington, DC: Georgetown University Press.

Bowen, B. D., Headley, D. E., \& Luedtke, J. R. (1992). A quantitative methodology for measuring airline quality. Journal of Aviation/Aerospace Education and Research, 2, 27-33.

Bowen, B. D., Headley, D. E., Kane, K. D., \& Lutte, R.K. (1999, October). Enhancing global competitiveness: Benchmarking airline operational performance in highly regulated environments. Collegiate Aviation Review, 17, 1-14.

Bryant, A. (1996, June 19). Conceding a conflict: Roles of watchdog and cheerleader can no longer co-exist at the FAA. New York Times, pp. A20- A23.

Carmines, E,G, \& Zeller, R.A. (1979). Reliability and validity assessment. Thousand Oaks, CA: SAGE.

Cary, P., Hedges, S. J., \& Walsh, K. T. (1996, July 1). The FAA s about-face. U.S. News \& World Report, p. 48-50.

Clark, A., \& Friedman, M. J. (1982). The relative importance of treatment outcomes: A Delphi group weighting in mental health. Evaluation Review, 6, 79-93.

Cronbach, L. J. (1951). Coefficient alpha and the internal structure of tests. Psychometrika, 16, 297-334.

Czaja, D., \& Blair, J. (1996). Designing surveys: A guide to decisions and procedures. Thousand Oaks, CA: Pine Forge.

Department of Transportation. (1998). Compliance and enforcement program. Washington, DC: U.S. Government Printing Office.

Dooley, D. (1995). Social research methods ( $3^{\text {rd }}$ ed.). Upper Saddle River, NJ: Prentice-Hall, Inc.

FAA s snail-pace response to safety threats adds risk. (1999, October 25). USA Today, p. 18A.

CA: Sage.

Folz, D. H. (1996). Survey research for public administration. Thousand Oaks,

Gleckman, H. (1996, July 15). A hard truth about deregulation. Business Week, 34.

Glieck, E. (1996, July 1). Can we ever trust the FAA? Time, 48-49.

Kingdon, J. W. (1995). Agendas, alternatives, and public policies. New York: Harper Collins.

Levinson, M., Underwood, A., \& Turque, B. (1996, July 1). A new day at the FAA? Newsweek, 46.

McMeniman, M. (1990). The use of judgmental data in developing an index for the quantification of learner needs. Evaluation and Program Planning, 13, 145-156.

National Transportation Safety Board. (2000). Accidents Involving Passenger Fatalities U.S. Airlines (Part 121) 1982 - Present. [On-line]. Available: http://www.ntsb.gov/aviation/paxfatal.htm.

Phillips, E. H. (1995, September 25). FAA offers proactive safety concept. Aviation Week \& Space Technology, 42.

Phillips, E. H. (1996, July 1). ValuJet hearings focus on FAA oversight. Aviation 
Week \& Space Technology, 29-31.

Phillips, E.H. (1997, February 3). FAA to expand airline safety data. Aviation Week \& Space Technology, 47-48.

Shifrin, C. A. (1996a, August 5). Ex-FAA official urges agency autonomy. Aviation Week \& Space Technology, 40.

Shifrin, C.A, (1996b, December 16). Safety experts seek data sharing. Aviation Week \& Space Technology, 25-27.

SAGE.

Spector, P. E. (1992). Summated rating scale construction. Newbury Park, CA:

Spiegel, M.R. (1996). Statistics. $\left(2^{\text {nd }}\right.$ ed.). NewYork: McGraw-Hill.

Stoller. G. (2000, March 13). Most fines get watered down: Airlines pay an average 25 cents on dollar. USA Today, p. 3B.

Ullmann, O. (1996, July 1). Wanted: A new flight plan for the FAA. Business Week, 39. 